\title{
EDUCATION
}

\section{Undergraduate training as preparation for vocational training in England: a survey of vocational dental practitioners' and their trainers' views}

\author{
J. Patel, ${ }^{1}$ K. Fox ${ }^{2}$, B. Grieveson ${ }^{3}$ and C. C. Youngson ${ }^{4}$
}

"There is
anecdotal
evidence that
vocational
trainers
perceive that
undergraduate
training has
been diluted
over the last
few years..."

SHO in Oral and Maxillofacia Surgery, Pinderfields General Hospital, Aberford Road, Wakefield, West Yorkshire, WF1 4DG; ${ }^{2}$ Clinical Lecturer in Restorative Dentistry, Liverpool Dental School, Pembroke Place, Liverpool, L3 5PS; ${ }^{3}$ Postgraduate Dental Dean, Mersey Dental Deanery, Regatta Place, Brunswick Business Park Summers Road, Liverpool, L3 $4 \mathrm{BL}$; ${ }^{4 *}$ Professor of Restorative Dentistry, Liverpool Dental School, Unit of Restorative Dentistry, Pembroke Place, Liverpool, L3 5PS;

${ }^{*}$ Correspondence to: Professor Callum Youngson Email: c.c.youngson@ liverpool.ac.uk

\begin{abstract}
Aims To compare the views of new vocational dental practitioners (VDPs) and their trainers regarding how undergraduate dental education has prepared them for their vocational training (VT) in England. This study also aims to identify areas of relative weakness in dental undergraduate education that could influence the future training needs of vocational trainees.

Method Structured postal questionnaires were completed by VDPs and trainers from five Deaneries in England. The usable response rate was 71\% ( $n=186$ VDPs and 186 trainers).

Results The vast majority of VDPs and trainers perceived the undergraduate training in history taking, diagnosis and treatment planning for general practice to have been covered 'well' or even 'very well'. Undergraduate training in routine restorative dentistry, oral pathology and paediatric dentistry was also perceived to have been covered well. However, a large proportion of VDPs and trainers reported that they felt that undergraduate training in orthodontics, molar endodontics, surgical endodontics and surgical extraction of teeth had not adequately prepared them for VT.

Conclusions Newly qualified dentists appear to lack certain competencies recommended by the General Dental Council in The First Five Years. This has implications for dental undergraduate education, but also highlights current training needs during VT.
\end{abstract}

\section{INTRODUCTION}

In October 1993, after a number of years as a voluntary scheme, a one-year period of vocational training (VT) became a mandatory requirement for all new UK dental graduates who wished subsequently to practice as a principal within the National Health Service. The General Dental Council (GDC) has strongly endorsed this arrangement, which 'allows a gradual and controlled transition from the shelter of undergraduate education to unsupervised practice. ${ }^{1}$

The GDC's document The First Five Years ${ }^{1}$ also provides a framework from which UK dental schools can structure their undergraduate curricula. The explicit overall aim is 'to produce a caring, knowledgeable, competent and skilful dentist who is able to accept professional responsibility for the effective and safe care of patients on graduation.'

Cabot and Radford suggested in $1999^{2}$ that the consumers of dental education are the patients, but also the graduates themselves, as it is they that are "purchasing' an education. But are new graduates fully satisfied with their 'purchase'?

In recent years there has been an increased interest in the issue of dental education, with the British Dental Journal recognising the importance of the topic by devoting a Section to it. However, although several papers have assessed the value of the vocational train- ing experience, there is a lack of research that reports the views of newly qualified dentists and VT trainers on how well the undergraduate course prepares for life in general practice. Those that do exist note that new graduates considered their undergraduate course to be lacking in some key areas ${ }^{3,4}$ and only one has been published since VT became mandatory. ${ }^{5}$ There is anecdotal evidence that vocational trainers perceive that undergraduate training has been diluted over the last few years and new graduates are not as capable, practically, as they once were. The primary aim of this current study, therefore, was to compare the current views of new vocational dental practitioners (VDPs) and their trainers, regarding how undergraduate dental education has prepared them for their VT in England. A secondary aim was to identify areas of relative weakness in dental undergraduate education that could influence the future training needs of vocational trainees, allowing the various under- and postgraduate authorities to plan future dental education more effectively.

\section{METHOD}

\section{The sample}

The sample was drawn from VDPs who commenced VT from August 2004 and their trainers. Questionnaires were posted to the following VT Deaneries in England: 
Yorkshire, South Yorkshire \& Trent, Northern, Mersey, and West Midlands. These Deaneries were selected as they had agreed to participate in the study. Following distribution by the local organisers, the participants posted the questionnaire using a reply-paid envelope to improve the response rate. A postal questionnaire was deemed to be the simplest and quickest method of obtaining mass information from VDPs and trainers located widely.

\section{The questionnaire}

Questionnaire design was informed by discussion with various VT advisors, dental academic staff and through a focus group of 12 VDPs and trainers from the Leicestershire VT scheme.

A pilot questionnaire was posted to 24 VDPs and their trainers within the Trent Deanery in March 2005. Twenty-four VDPs (100\%) and 19 trainers (79\%) responded. The final, anonymous, questionnaires were then distributed by VT organisers to the Deaneries noted above in April 2005. The structure of the questionnaire sent to the VDPs is shown in Figure 1.

Each VDP and trainer completed identical surveys. Each trainer stated the number of years they had been a VT trainer and each VDP was asked to indicate their gender and the dental school from which they graduated. The participants' attitudes were measured using a four-point scale. Each participant selected 1, 2, 3 or 4 for each of the clinical areas mentioned in the survey ( 1 = very well prepared, 2 = well prepared, 3 = poorly prepared, 4 = very poorly prepared).

\section{RESULTS}

Of the 522 questionnaires that were posted, 372 were returned (186 VDPs and 186 VT trainers). There was a usable response rate of $71 \%$ after incomplete papers were discarded. Of the VDP respondents, 113 (61\%) were male and 73 (39\%) female. An average of 4.3 years involvement in vocational training was noted amongst the respondent trainers.

Table 1 demonstrates that the respondents originated from a range of dental schools (nine out of a potential 13 undergraduate UK dental schools). Table 2 shows the response rate in relation to each VT Deanery. The responses were divided into the categories listed below.

\section{Patient assessment}

For history taking and examination of patients, nearly all of the VDPs (97\%) believed they were prepared 'well' or 'very well' by their undergraduate course. The vast majority of VT trainers (93\%) agreed with this.

Fifty-six percent of trainers felt that new graduates were 'poorly' or 'very poorly' prepared for diagnosis and treatment planning in general practice and this supports anecdotal evidence where trainers have reported that VDPs have difficulty dealing with patients in acute pain, especially with regard to reaching an accurate diagnosis and carrying out appropriate treatment to relieve pain. However, this contrasts with the perception of the majority of VDPs (82\%), who felt confident in this aspect of clinical practice.

\section{Oral surgery}

The majority of VDPs (87\%) and trainers (77\%) surveyed were satisfied with undergraduate experience of non-surgical extraction of teeth. However, both groups agreed that undergraduate experience of surgical extractions was either 'poor' or 'very poor' (VDPs 77\%, trainers 83\%). Another area regarded as being inadequately covered at undergraduate level was surgical endodontics, with both groups considering training in this field to be inadequate (VDPs 82\%, trainers 84\%).

\section{Oral medicine/pathology}

The vast majority of VDPs (91\%) and trainers (84\%) perceived training in the management of red/white lesions to have been covered well. The results also highlight confidence amongst both groups with regards to prescribing drugs (VDPs 81\%, trainers 79\%) and in the management of recurrent ulcers (VDPs 93\%, trainers 95\%) and dry mouth (VDPs 87\%, trainers 86\%).

\section{Orthodontics}

Sixty percent of VDPs surveyed were not confident with orthodontic case assessment, 72\% with the use of fixed appliances and 55\% with the use of removable appliances. These views are supported by their trainers. Only 50\% of trainers considered new graduates to be prepared 'well' or 'very well' for orthodontic case assessment in general practice. The respondent trainers also perceived an inadequacy in undergraduate orthodontic training with regards to fixed appliances (87\%), removable appliances (70\%) and in the management of the mixed dentition (65\%).

\section{Practice management and clinical governance}

A large proportion of trainers reported new graduates as having 'poor' or 'very poor' training in practice management skills such as staff management (85\%), employment law (89\%) and health \&t safety (84\%). The vast majority of VDPs agreed with these views.

It is clear that most VDPs (61\%) and trainers (71\%) believe new graduates are well versed in the need for continuing professional development (CPD) after graduation. With regards to other aspects of clinical governance, only a small number of VDPs and trainers were satisfied with undergraduate training in audit and peer review for general practice (VDPs 18\%, trainers 20\%).

\section{Conservative dentistry}

Ninety-seven percent of VDPs and trainers perceived training in restorative materials to have been adequately covered during the undergraduate course. The great majority of VDPs (92\%) and trainers (92\%) were also happy with the training received for the management of dentine hypersensitivity. Training received for the management of tooth substance loss (TSL) was also considered to have been covered well at dental school 
Fig. 1 VDP questionnaire

1. Which Dental School did you graduate from?

2. Gender? (M/F)

3. How well do you feel the teaching, of the following subjects, prepared you for your VT year? Please answer: 1) Very Well 2) Well 3) Poorly 4) V. Poorly (Tick box)

\begin{tabular}{|l|l|l|l|l}
\hline & 1 & 2 & 3 & 4 \\
\hline History taking & & & & \\
\hline Diagnosis \& Rx planning & & & & \\
\hline ORALSURE & & & \\
\hline
\end{tabular}

ORAL SURGERY

Extraction techniques (non-surgical)

Dento-alveolar surgery

Surgical endodontics

Management of continued bleeding

Management of impacted teeth (eg 8's)

Management of an OAC/OAF

Local anaesthesia

Analgesia/antibiotics

ORAL MEDICINE

Management of red/white patches

Prescribing drugs/drug reactions

Management of recurrent ulcers

Management of dry mouth

ORTHODONTICS

Case assessment

Removable appliances

Fixed appliances

Management of the mixed dentition

OTHER AREAS

Career pathways

Staff management

CPD

Audit \& peer review

Employment law

Health \& safety

RESTORATIVE

Restorative materials

Complex endodontics (eg molar endo)

Crown \& bridge

Tooth whitening

Management of tooth wear

Management of dentine hypersensitivity

PROSTHETICS

$\mathrm{F} / \mathrm{F}$ dentures

$\mathrm{P} / \mathrm{P}$ acrylic

$\mathrm{P} / \mathrm{P}$ Co-Cr

Immediate dentures

Impression techniques \& materials

PAEDODONTICS

Behaviour mgt

Trauma

Restorative techniques

Sedation techniques

PERIODONTOLOGY

Non-surgical therapy

Local \& systemic antimicrobial treatment

Crown lengthening surgery

\begin{tabular}{|l|l|l|l|}
\hline & & & \\
\hline & & & \\
\hline & & & \\
\hline & & & \\
\hline & & & \\
\hline & & & \\
\hline
\end{tabular}

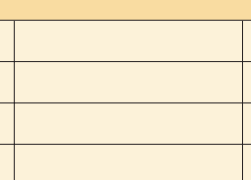

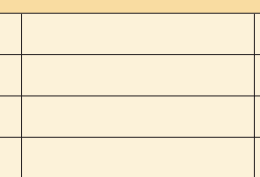

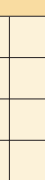

4

Comments: 


"Of the
trainers
surveyed, most
perceived
undergraduate
training in the
construction
of immediate
dentures to
be poor, while
the majority
of VDPs were
content with
their training
in this field."

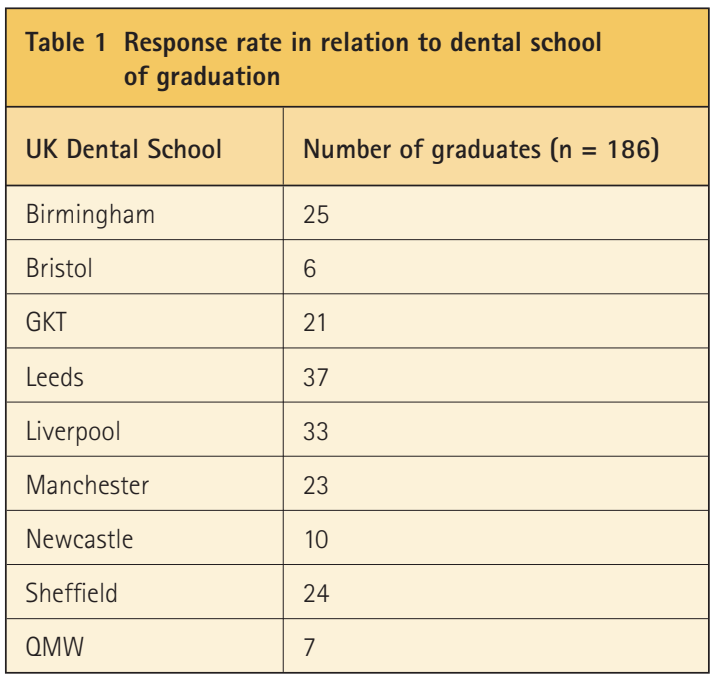

Table 2 Response rate in relation to each VT deanery

\begin{tabular}{|l|l|}
\hline Deanery & Response rate (\%) \\
\hline Trent \& S. Yorkshire & 67 \\
\hline Mersey & 83 \\
\hline Northern & 71 \\
\hline W. Midlands & 60 \\
\hline Yorkshire & 69 \\
\hline
\end{tabular}

(VDPs 86\%, trainers 78\%). However, most trainers (71\%) were disappointed with the training received for crown and bridge work, stating this to have been 'poorly' or even 'very poorly' covered. About half of the VDPs (55\%) agreed with this statement.

Of the VDPs surveyed, most expressed a lack of preparedness with regards to complex/molar endodontics, with 66\% rating their preparedness as 'poor' and 3\% 'very poor'. The majority of trainers (74\%) agreed with this view. Both groups were also dissatisfied with the preparedness in tooth whitening methods (VDPs 91\%, trainers $84 \%$ ).

\section{Periodontology}

The majority of VDPs and trainers regarded undergraduate training in periodontology highly, with 'well' and 'very well' being the most common responses. This was especially true for non-surgical therapy (VDPs 98\%, trainers 96\%) and the use of antimicrobials (VDPs 86\%, trainers 83\%) in the treatment of periodontal disease.

\section{Prosthodontics (removable)}

Of the trainers surveyed, most (68\%) perceived undergraduate training in the construction of immediate dentures to be poor, compared to the majority of VDPs $(82 \%)$ who were content with their training in this field. Overall, the majority of VDPs believed they were prepared adequately at dental school for the construction of removable prostheses in general practice.

\section{Paediatric dentistry}

Both groups were found to be satisfied with the training received in paediatric dentistry as a whole. With regard to the restoration of primary teeth, VDPs (90\%) and the trainers $(96 \%)$ believed training to have been adequately covered. Both groups also considered new graduates to be 'well' or 'very well' trained in behaviour management techniques for children (VDPs 95\%, trainers 91\%).

The majority of VDPs (68\%) were also content with the level of undergraduate training received in sedation techniques. However, this view was not supported by the trainers, where slightly over half (53\%) considered undergraduate training in this field to be either 'poor' or 'very poor'.

The overall responses from the VDPs and trainers are summarised in Tables 3 and 4. Tables 5 and 6 show the full ranges of scores given by the respective groups.

\section{DISCUSSION}

The results of this study demonstrate the opinions of a group of 186 VDPs and 186 VT trainers, regarding the undergraduate dental education of the VDPs. The results were not broken down by dental school, as some schools were not adequately represented and other schools were not represented at all. In recognition of the fact that there are organisational differences in the constituent countries of the UK, this study examined only VDPs and trainers in England.

A questionnaire, returned by post, was deemed to be the simplest and quickest method of obtaining mass information from VDPs and trainers located widely throughout England. One mail-shot, distributed by each regional VT organiser and including a pre-paid envelope, produced an adequate response rate (71\%) and so non-respondents were not contacted for a second time. It is, however, conceivable that this may have influenced the obtained results. Interviews were not performed in this study, but may provide valuable and detailed information if carried-out in future investigations.

This qualitative assessment was conducted on a self-selected sample, in that it was these 372 people who decided to participate in this study by returning completed questionnaires from the Deaneries that had agreed to take part. An attempt to reduce the risk of including bias in the questionnaire, regarding preconceptions of undergraduate education, was made via a pilot study of VDPs and through discussions with various VT organisers and dental academic staff. The final list of questions was not exhaustive but reflected concerns highlighted during the piloting process. A four, rather than five point scale was used, with omission of a mid point of 'satisfactorily prepared' in an attempt to concentrate the minds of the respondents and prevent a 'drift towards the mean' that could have masked the positive or negative views. There may be merit in repeating this study in other areas in the UK to determine if these results are representative of a truly national trend. 
Table 3 A summary of the clinical fields perceived as being 'poorly' or 'very poorly' covered at undergraduate level

\begin{tabular}{|l|l|l|}
\hline Clinical field & $\%$ VDP (n) & $\begin{array}{l}\% \text { VT } \\
\text { trainer (n) }\end{array}$ \\
\hline Surgical extractions & $77 \%(143)$ & $83 \%(155)$ \\
\hline Surgical endodontics & $82 \%(152)$ & $84 \%(156)$ \\
\hline $\begin{array}{l}\text { Complex/molar } \\
\text { endodontics }\end{array}$ & $69 \%(128)$ & $74 \%(138)$ \\
\hline $\begin{array}{l}\text { Tooth whitening } \\
\text { techniques }\end{array}$ & $91 \%(169)$ & $84 \%(157)$ \\
\hline Crown \&t bridge work & $55 \%(103)$ & $71 \%(132)$ \\
\hline $\begin{array}{l}\text { Orthodontic removable } \\
\text { appliances }\end{array}$ & $55 \%(102)$ & $70 \%(131)$ \\
\hline $\begin{array}{l}\text { Orthodontic fixed } \\
\text { appliances }\end{array}$ & $72 \%(133)$ & $87 \%(162)$ \\
\hline $\begin{array}{l}\text { Orthodontic management } \\
\text { of mixed dentition }\end{array}$ & $37 \%(68)$ & $65 \%(121)$ \\
\hline Staff management & $88 \%(163)$ & $85 \%(159)$ \\
\hline Employment law & $87 \%(161)$ & $89 \%(165)$ \\
\hline Health \&t safety & $79 \%(147)$ & $84 \%(157)$ \\
\hline Sedation techniques & $32 \%(59)$ & $52 \%(96)$ \\
\hline $\begin{array}{l}\text { Diagnosis and treatment } \\
\text { planning }\end{array}$ & $18 \%(33)$ & $56 \%(105)$ \\
\hline
\end{tabular}

Table 4 A summary of the clinical fields perceived as being 'well' or 'very well' covered at undergraduate level

\begin{tabular}{|l|l|l|}
\hline Clinical field & $\%$ VDP (n) & $\begin{array}{l}\% \text { VT } \\
\text { trainer (n) }\end{array}$ \\
\hline History taking \&t examination & $97 \%(180)$ & $93 \%(173)$ \\
\hline $\begin{array}{l}\text { Extraction techniques } \\
\text { (non-surgical) }\end{array}$ & $87 \%(162)$ & $77 \%(144)$ \\
\hline $\begin{array}{l}\text { Management of continued } \\
\text { bleeding }\end{array}$ & $69 \%(128)$ & $74 \%(138)$ \\
\hline $\begin{array}{l}\text { Management of red/ } \\
\text { white patches }\end{array}$ & $91 \%(169)$ & $84 \%(157)$ \\
\hline $\begin{array}{l}\text { Drug prescribing and } \\
\text { drug reactions }\end{array}$ & $81 \%(150)$ & $79 \%(147)$ \\
\hline $\begin{array}{l}\text { CPD } \\
\text { Restorative materials }\end{array}$ & $91 \%(113)$ & $71 \%(132)$ \\
\hline $\begin{array}{l}\text { Management of dentine } \\
\text { hypersensitivity }\end{array}$ & $92 \%(171)$ & $92 \%(171)$ \\
\hline $\begin{array}{l}\text { Complete/Complete denture } \\
\text { construction }\end{array}$ & $94 \%(175)$ & $88 \%(167)$ \\
\hline $\begin{array}{l}\text { Behaviour management } \\
\text { in children }\end{array}$ & $95 \%(176)$ & $91 \%(170)$ \\
\hline $\begin{array}{l}\text { Non-surgical periodontal } \\
\text { therapy }\end{array}$ & $98 \%(183)$ & $96 \%(174)$ \\
\hline $\begin{array}{l}\text { Diagnosis and treatment } \\
\text { planning }\end{array}$ & $82 \%(153)$ & $44 \%(81)$ \\
\hline
\end{tabular}

The results of this study confirm earlier research by Levine in $1992^{6}$ that new graduates are satisfied with the level of undergraduate experience gained in the basic skills needed to cope with their first year in general practice. A difference in perception between the VDP and VT trainer can however exist, and this is particularly noticeable in the groups' different perceptions regarding preparedness for diagnosis and treatment planning. It could be suggested that, in general, the VDPs lack sufficient insight to be aware of their deficiencies in this area, whereas the experienced trainers notice it acutely.

It is common in general practice to encounter children requiring orthodontic treatment. The GDC's document The First Five Years ${ }^{1}$ advises that 'the student should be able to apply the principles of orthodontics in practice and to recognise the limitations that exist in that situation. This involves the ability to carry-out diagnostic procedures, formulate treatment plans and relate them to comprehensive patient care'. Although orthodontics is often considered to be a 'postgraduate' subject, it is evident from this study that a considerable proportion of VDPs and trainers surveyed considered undergraduate orthodontic training as inadequate for treatment but reasonable for case assessment.

That document ${ }^{1}$ also recommends that students 'should be able to undertake the extraction of teeth and removal of roots where no major complications are anticipated. It is clear from the results that the majority of VDPs and VT trainers surveyed believe new graduates need more clinical experience with regards to transalveolar (surgical) extraction of teeth. This perceived lack of undergraduate experience in orthodontics and surgical extractions has been highlighted by previous studies. ${ }^{3-7}$ Similarly, the results of the current study are also consistent with previous studies, which have shown newly qualified dentists to be lacking confidence with crown and bridgework and complex endodontics., ${ }^{5,8}$ It is clear that, despite the passage of time, these issues are still to be adequately addressed. Bartlett et al. ${ }^{7}$ suggested in 2001 that this lack of clinical experience may be due to dental schools taking the attitude that confidence in all these skills are more effectively developed in general practice, and therefore have concentrated on providing a basic understanding of the principles alone. Although this may be the case, the GDC's The First Five Years ${ }^{1}$ is fairly unambiguous in the competencies it would expect a new graduate to have obtained from a 'sufficient' dental school.

Other, non-clinical, areas where VDPs felt under-prepared relate to practice management skills and clinical governance. This finding reinforces the suggestion by Meadows et al. in $1998^{9}$ that there is a need for dental education to address the wider role and responsibilities of the dentist.

Some aspects of the curriculum do not appear to have responded to changes in clinical practice or patient expectations, such as tooth whitening techniques, and it is worth recording that curricula should be sufficiently flexible to develop and reflect developments in 
Table 5 Range of responses from VDPs

\begin{tabular}{|l|l|l|l|l|}
\hline $\begin{array}{l}\text { Preparation during undergraduate } \\
\text { training }\end{array}$ & Very well covered & Well covered & Poorly covered & $\begin{array}{l}\text { Very poorly } \\
\text { covered }\end{array}$ \\
\hline History taking & 82 & 98 & 6 & 0 \\
\hline Diagnosis \& treatment planning & 43 & 110 & 33 & 0 \\
\hline Extraction techniques (non-surgical) & 64 & 98 & 23 & 1 \\
\hline Surgical extractions & 6 & 37 & 119 & 24 \\
\hline Surgical endodontics & 1 & 33 & 122 & 30 \\
\hline Drug prescribing and drug reactions & 47 & 103 & 34 & 2 \\
\hline Orthodontic removable appliances & 6 & 78 & 85 & 17 \\
\hline Orthodontic fixed appliances & 11 & 42 & 113 & 20 \\
\hline Management of the mixed dentition & 14 & 104 & 56 & 12 \\
\hline Staff management & 1 & 22 & 136 & 27 \\
\hline Employment law & 0 & 25 & 119 & 42 \\
\hline CPD & 20 & 93 & 60 & 13 \\
\hline Health and safety & 6 & 33 & 112 & 35 \\
\hline Complex/molar endodontics & 8 & 50 & 122 & 6 \\
\hline Crown \&t bridge & 16 & 67 & 98 & 5 \\
\hline Tooth whitening & 1 & 16 & 122 & 47 \\
\hline Restorative materials & 113 & 67 & 6 & 0 \\
\hline Dentine hypersensitivity & 69 & 102 & 13 & 2 \\
\hline Complete/Complete denture construction & 55 & 120 & 8 & 3 \\
\hline Non-surgical therapy & 128 & 55 & 3 & \\
\hline Sedation techniques & 42 & 66 & 9 \\
\hline Behaviour management in children & 110 & & \\
\hline & & 57 & \\
\hline
\end{tabular}

clinical practice based on scientific evidence.

The perceived deficiency of these undergraduate courses to adequately prepare the responding new graduates to perform some forms of treatment (eg surgical endodontics) may reflect the recognition within teaching hospitals that not all procedures are appropriate for newly qualified practitioners. The presence of several dental specialties in the UK with appropriate training programmes allows a continuum of training and there is a tendency for some procedures, formerly performed routinely in general practice, to be seen increasingly as 'specialist' in nature.

The findings of this study do not imply criticism of any undergraduate course, but draw attention to areas where dental schools may want to examine the adequacy of their training. The increase in undergraduate student numbers for most dental schools that commenced in 2005, coupled with a difficulty in recruiting or retaining academic staff, ${ }^{10}$ may make this task difficult to achieve. The 'Walport Report' ${ }^{\text {'1 }}$ may address the recruitment of highly competent academic researcher/ clinicians, but this may not result in recruiting and retaining clinical teachers in dentistry, where career progress is often based on research excellence but the main role is delivering chairside tuition. This is unfortunate as it is the number of teachers that currently requires expansion.

The graduates' preparedness should be monitored over the next few years. Not only will the graduates of 2010/2011 be directly affected, but as the increased numbers of students feed through the system there is a risk that existing cohorts will receive less close supervision during their clinical undergraduate training. The results of the current study suggest that there are difficulties providing sufficient clinical experience and teaching time during the undergraduate course, so the role of vocational training is becoming increasingly important.

There is agreement, and an acceptance, among trainers that VDPs have different training needs and there should be an initial interview to target and identify areas of perceived clinical weakness. Targeted training can then take place during the VT period. In some clinical areas, particulary endodontics and bridgework, current undergraduate teaching may not include what is normal practice in the primary care setting. Vocational training builds skills on top of the basic knowledge of undergraduates in many clinical areas as the VDP's confidence develops throughout the year with the guidance and support of the trainer.

Hobson in $1998^{12}$ discussed how vocational training has formalised and improved training given to new graduates. It is also clear that vocational trainers make an important contribution to dental education, as it is they that can provide one-to-one teaching in clinical areas where new graduates are deficient. 


\section{Table 6 Range of responses from VT trainers}

\begin{tabular}{|l|l|l|l|l|}
\hline Preparation during undergraduate traning & Very well covered & Well covered & Poorly covered & Very poorly covered \\
\hline History taking & 68 & 105 & 13 & 0 \\
\hline Diagnosis \& treatment planning & 10 & 71 & 104 & 1 \\
\hline Extraction techniques (non-surgical) & 23 & 121 & 42 & 0 \\
\hline Surgical extractions & 4 & 27 & 122 & 33 \\
\hline Surgical endodontics & 3 & 27 & 120 & 36 \\
\hline Drug prescribing and drug reactions & 32 & 115 & 36 & 3 \\
\hline Orthodontic removable appliances & 2 & 53 & 116 & 15 \\
\hline Orthodontic fixed appliances & 1 & 23 & 130 & 32 \\
\hline Management of the mixed dentition & 8 & 57 & 110 & 11 \\
\hline Staff management & 3 & 24 & 133 & 26 \\
\hline Employment law & 5 & 16 & 128 & 37 \\
\hline CPD & 11 & 121 & 44 & 10 \\
\hline Health and safety & 2 & 27 & 113 & 44 \\
\hline Complex/molar endodontics & 20 & 28 & 122 & 16 \\
\hline Crown \&t bridge & 10 & 44 & 116 & 16 \\
\hline Tooth whitening & 2 & 27 & 135 & 22 \\
\hline Restorative materials & 89 & 91 & 6 & 0 \\
\hline Dentine hypersensitivity & 31 & 140 & 15 & 0 \\
\hline Complete/Complete denture construction & 43 & 124 & 15 & 4 \\
\hline Non-surgical therapy & 77 & 102 & 7 & 0 \\
\hline Sedation techniques & 13 & 77 & 87 & 9 \\
\hline Behaviour management in children & 66 & 104 & 15 & 1 \\
\hline & & & \\
\hline
\end{tabular}

Thus, it is important that dental schools communicate with VT organisers regularly, as feedback is essential to improving dental undergraduate education in the future. One previous recommendation has been for VT liaison officers to be integrated into undergraduate dental school strategy and planning ${ }^{13}$ and the results of the current study suggest that this should become standard practice.

\section{CONCLUSIONS}

1. The results of this study were obtained from a selfselected sample and therefore the results cannot be generalised to new graduates nationwide.

2. Newly qualified dentists perceive a lack of training in their undergraduate course that would enable them to fulfil certain competencies (molar endodontics, surgical extractions, orthodontics and crown and bridgework) stipulated by the GDC.

3. Where present, these deficiencies should be targeted during their vocational training.

JP would like to thank personally Dr Jayanti Chauhan, VT trainer, for his input into this study and for his ongoing support. All the authors would also like to thank the various VT organisers, trainers and VDPs who facilitated this research.
1. General Dental Council. The first five years: the undergraduate dental curriculum. 2nd ed. London: General Dental Council, 2002.

2. Cabot $L B$, Radford D R. Are graduates as good as they used to be? BrDent J 1999; 186: 318-319.

3. Murray F J, Blinkhorn A S, Bulman J. An assessment of the views held by recent graduates on their undergraduate course. Eur J Dent Educ 1999; 3: 3-9.

4. Silversin J B, Shafer S M, Smales F C, Sheiham A. British dentists' and final year British and United States students' opinions about their undergraduate training. Br Dent J 1974; 137: 161-168.

5. Kay E J, Blinkhorn A S. Scottish dental students' views on their undergraduate training. Br Dent J 1987; 162: 317-319.

6. Levine R S. Experience, skill and knowledge gained by newly qualified dentists during their first year in general practice. Br Dent J 1992; 172: 97-102.

7. Bartlett D W, Coward PY, Wilson R, Goodsman D, Darby J. Experiences and perceptions of vocational training reported by the 1999 cohort of vocational dental practitioners and their trainers in England and Wales. Br Dent J 2001; 191: 265-270.

8. Bookham D J. Vocational trainees' views of their undergraduate endodontic training and their vocational training experience. Int

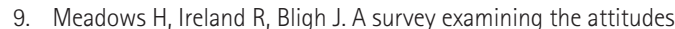
of general dental practitioners toward change in undergraduate

10. Clinical academic staffing levels in UK medical and dental schools. London: Council of Heads of Medical Schools, 2004.

11. Medically and dentally qualified staff. Recommendations for training the researchers and educators of the future. (The Walport Report). London: The academic sub-committee of UKCRC and Modernising Medical Careers, 2005.

12. Hobson R. The competent graduate. Br Dent J 1998; 184: 156.

13. Guidance for vocational training. London: Committee on Vocational Training for England and Wales, 1993. Endod J 1991; 24: 178-186 dental education. Br Dent J 1998; 184: 401-404.
"... it is

important that dental schools communicate with VT organisers regularly, as feedback is essential to improving dental undergraduate education in the future." 